Corrigendum

\title{
Corrigendum to "Migration of the Anterior Spinal Rod to the Right Thigh, a Rare Complication of Anterior Spinal Instrumentations: A Case Report and a Literature Review"
}

\author{
Gaston Camino Willhuber, Danilo Taype Zamboni, Guido Carabelli, \\ Jorge Barla, and Carlos Sancineto
}

Institute of Orthopedics “Carlos E. Ottolenghi," Italian Hospital of Buenos Aires, Juan D. Peron 4190, C1181ACH Buenos Aires, Argentina

Correspondence should be addressed to Danilo Taype Zamboni; danilo.taype@hospitalitaliano.org.ar

Received 22 August 2016; Accepted 18 September 2016

Copyright (c) 2016 Gaston Camino Willhuber et al. This is an open access article distributed under the Creative Commons Attribution License, which permits unrestricted use, distribution, and reproduction in any medium, provided the original work is properly cited.

In the article titled "Migration of the Anterior Spinal Rod to the Right Thigh, a Rare Complication of Anterior Spinal Instrumentations: A Case Report and a Literature Review" [1], the authors' first and last names were reversed. The corrected authors' list is shown above.

\section{References}

[1] C. W. Gaston, T. Z. Danilo, C. Guido, B. Jorge, and S. Carlos, "Migration of the anterior spinal rod to the right thigh, a rare complication of anterior spinal instrumentations: a case report and a literature review," Case Reports in Orthopedics, vol. 2015, Article ID 532412, 4 pages, 2015. 


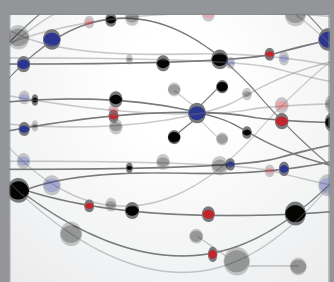

The Scientific World Journal
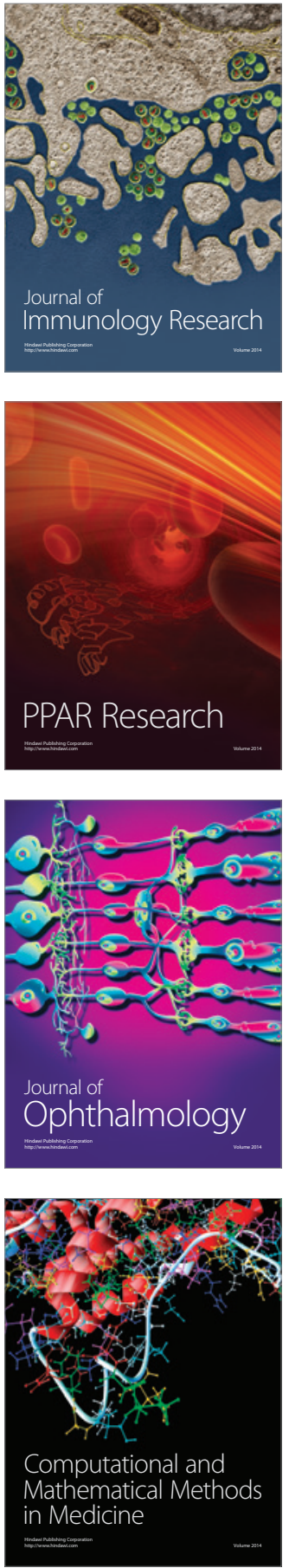

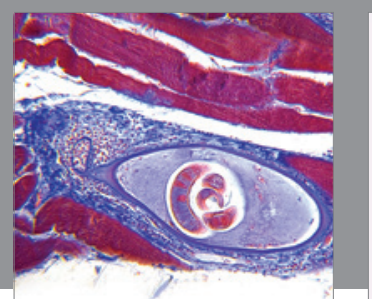

Gastroenterology Research and Practice

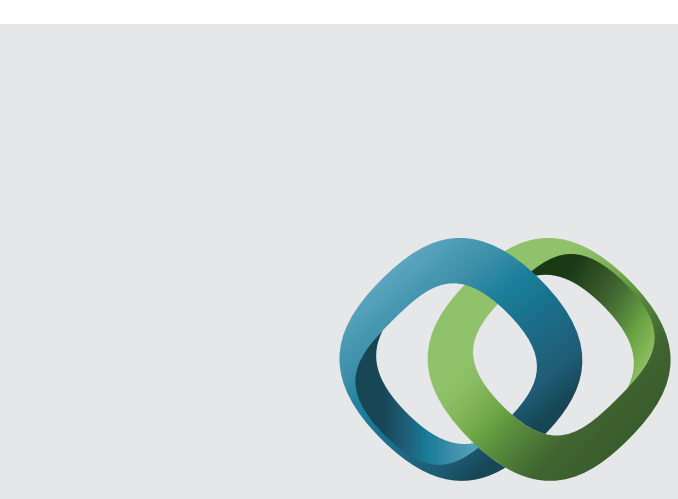

\section{Hindawi}

Submit your manuscripts at

http://www.hindawi.com
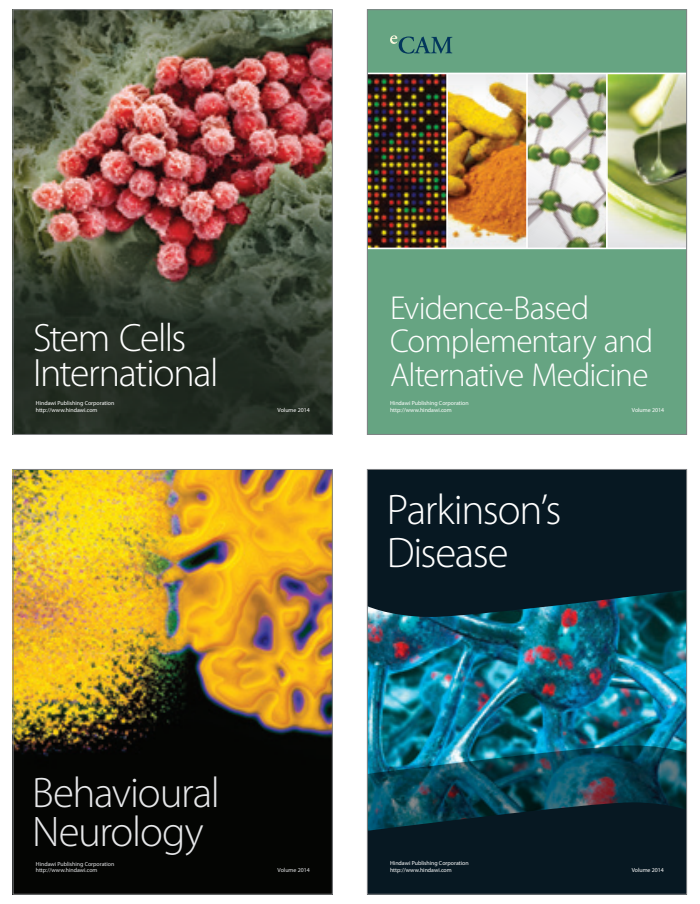
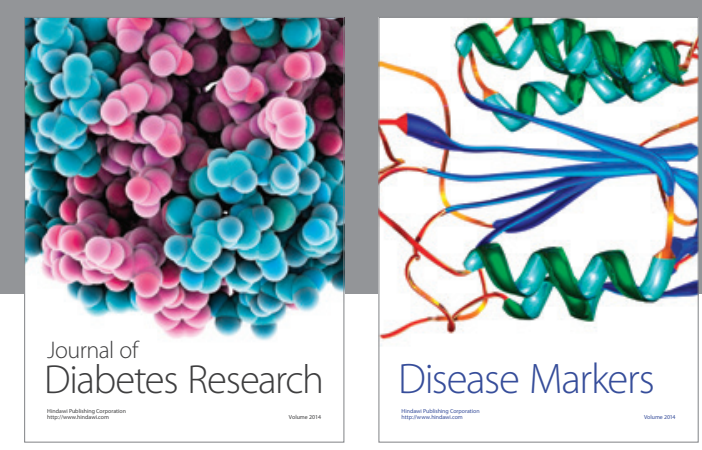

Disease Markers
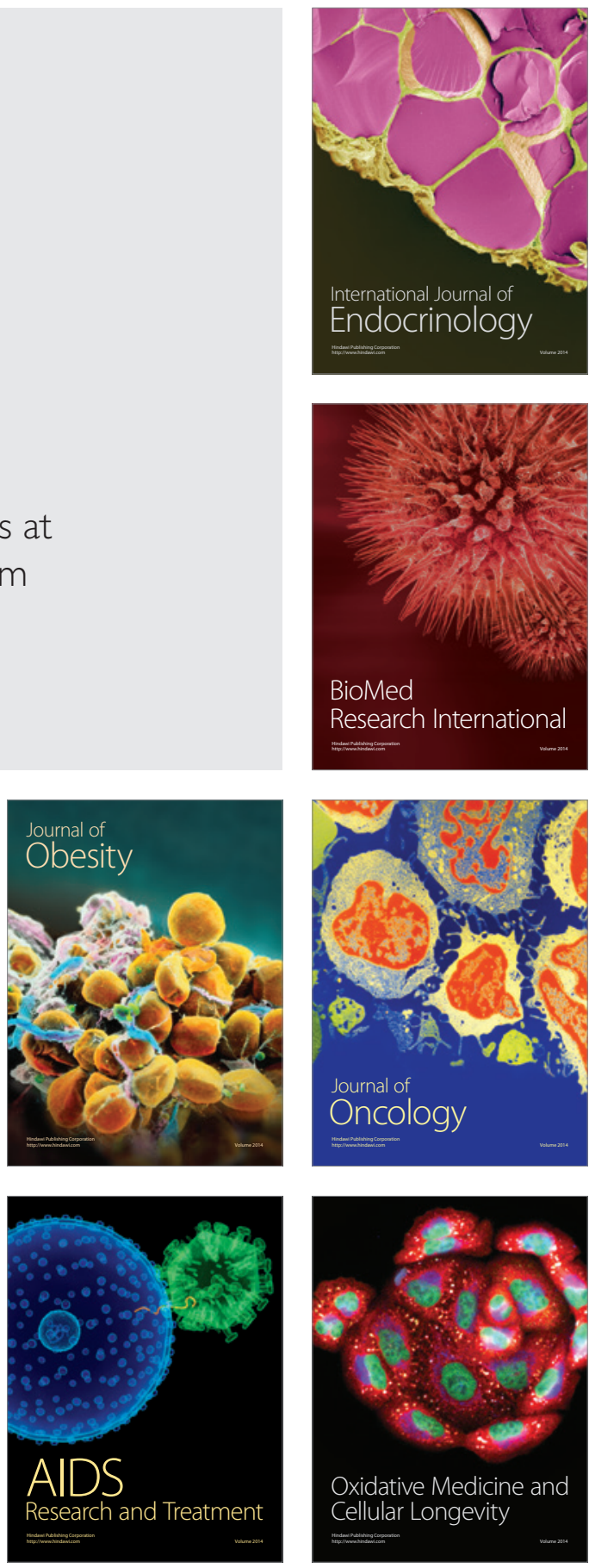